\title{
Detailed Thermal Design and Control of an Observation Satellite in Low Earth Orbit
}

\author{
Hilmi Sundu ${ }^{1,2, *}$ (D) Nimeti Döner ${ }^{1}$ (D) \\ 'Gazi University, Faculty of Engineering, Department of Mechanical Engineering, Maltepe, Ankara, Turkey \\ ${ }^{2}$ Tubitak Space Technologies Research Institute, Cankaya, Ankara, Turkey
}

\begin{abstract}
The thermal environment in space presents challenging conditions, including vacuum, low pressure, atomic oxygen, and extremes of hot and cold. Satellites consist of electronic equipment which needs to be maintained within a certain temperature range during the operation period. The thermal design and control of observation satellites in low Earth orbit (LEO) are therefore very important. In our study, we present the thermal design and analysis of LEO observation satellites. A satellite was designed and modelled using Systema Thermica v.4.8.P1 software with the Monte-Carlo ray tracing method. Analyses were performed for two extreme scenarios with (i) extreme hot and (ii) extreme cold temperatures. The areas, temperatures, and locations of the radiators on the satellite panels were analysed under the hot scenario, while the power and operating conditions of the heaters were evaluated based on the cold scenario. As a result, in the hot condition, a total radiator area of $0.6972 \mathrm{~m}^{2}$ was used. The cold condition required a heating power of $25.06 \mathrm{~W}$ for the most critical battery in the satellite. It was observed that the temperatures of the electronic equipment on the satellite must be within the desired temperature range throughout the observation process. This temperature range is different for each type of equipment; for instance, batteries need to be between $0^{\circ} \mathrm{C}$ and $+30^{\circ} \mathrm{C}$, while electronic equipment must be between $-20^{\circ} \mathrm{C}$ and $+50^{\circ} \mathrm{C}$.
\end{abstract}

Keywords: Observation satellite, thermal control, finite volume analysis, Monte-Carlo ray tracing, radiative transfer

\section{INTRODUCTION}

Observation satellites are generally used in the monitoring of disasters, and for intelligence and security purposes. Satellites contain electronic equipment that must operate within a certain temperature range throughout its service life. Thermal control systems comprise three steps: thermal design, thermal analysis, and thermal testing. After a thermal analysis has been performed, the thermal design is optimised and verified using thermal balance tests. In addition, thermal control techniques can be classified into passive and active methods. Multi-layer insulation (MLI), optical solar reflectors (OSRs), thermal interface fillers, and thermal coatings (e.g., second surface mirrors) are passive methods of control, while the heaters and thermistors in satellites are active techniques [1]. A passive control technique works naturally, without consuming power, whereas an active control technique is powered by electricity. Thermocouples are also used to verify the temperature of equipment during thermal balance testing [2]. Thermal design and control are commonly used for research subjects such as CubeSat and na- nosatellites, which are represented by a single node and have been investigated in many studies [3-8]. However, no papers have been published on how to design and control a satellite in low Earth orbit (LEO). Coker [3] conducted a thermal analysis of the Edison Demonstration of Smallsat Networks (EDSN) CubeSat, and showed that thermal design is sensitive to problems such as extreme cold and hot temperatures. The thermal analysis of 1.5 CubeSat of EDSN was performed to assess the temperatures of the components using Thermal Desktop software. Moffit et al. [4] studied the thermal modeling of the Combat Sentinel Satellite (CSSAT), and also used SDRC-I for thermal model generation. Bulut et al. [5] studied the CubeSat model and performed a thermal analysis using a spreadsheet-based tool called ThermXL. Mishra [6] presented a thermal control method for CubeSat at heights of 98.1 and $580 \mathrm{~km}$ in LEO, and used only a passive control technique due to its cost efficiency. However, thermistor heaters were not used for the cold scenario. Tsai [7] proposed a simple thermal analytical method of solving the satellite thermal model, which included a single node and
* Corresponding authour

Email: hilmi.sundu@tubitak.gov.tr
European Mechanical Science (2020), 4(4): 171-178 doi: https://doi.org/10.26701/ems.730201

Received: April 30, 2020

Accepted: July 18, 2020 
an average temperature. Garzon [8] presented a Master's thesis on OSIRICI-3U CubeSat. Thurman [9] proposed an analytical approach to the optimum thermal design of space radiators. Similarly, Aslanturk[10] studied the optimisation of a central-heating radiator.

In this study, a thermal analysis and a detailed model for the thermal control of a satellite in LEO were performed using Thermica V4.8.P1. Unlike previous studies related to satellites in LEO, the effects of radiators and heaters on the satellite were also included in our study. The optimum thermal design was produced.

\section{THERMAL ENVIRONMENTAL EFFECTS ON A SPACE SATELLITE}

LEO satellites operate at distances of between about 500 and $1500 \mathrm{~km}$, and are subjected to various external thermal loads. These loads include the heat flux incident from the Sun, the flux from the Earth, and the reflection of solar rays from the Earth, which is refered to as the albedo. Figure 1 represents the external thermal loads on a satellite.

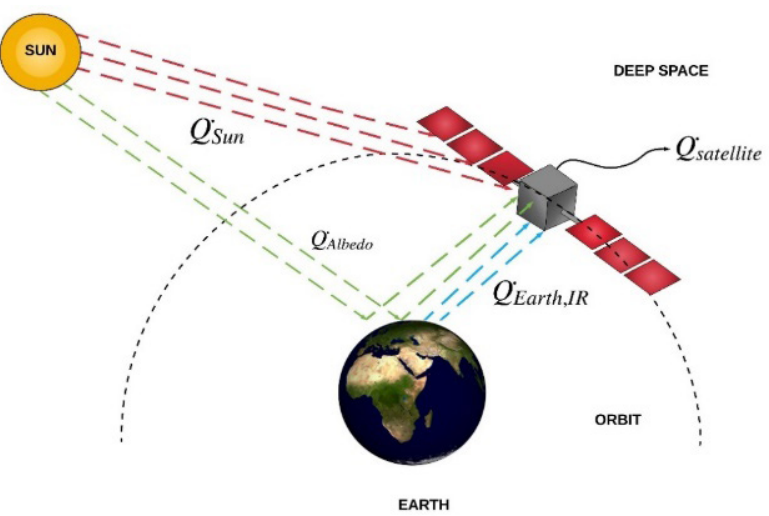

Figure 1. Schematic view of the external loads on a satellite.

Due to the elliptical orbit of the Earth, solar flux changes with the season of the year. When the Earth is closest to the Sun, i.e. at the winter solstice of the northern hemisphere, the solar flux reaches a maximum value of $1414 \pm 5 \mathrm{~W} / \mathrm{m}^{2}$, whereas the minimum value of the solar flux is $1317 \pm 5 \mathrm{~W} /$ $\mathrm{m}^{2}$ and occurs when the Earth is the farthest from the Sun, at the summer solstice [1]. The albedo flux is defined as the percentage of the radiation from the Sun that is reflected into deep space. The nominal albedo value is about $30 \% \pm$ $10 \%$ of the solar flux; however, this is based on an average value of around $237 \pm 21 \mathrm{~W} / \mathrm{m}^{2}$ emitted from the earth's surface. This value is not constant, and varies depending on the surface properties of the Earth.

Some of the solar flux reaching Earth is emitted as longwave infra-red (IR) radiation due to the temperature of the Earth. The Earth can be considered as a black body, and its effective blackbody temperature is assumed to be $255 \mathrm{~K}$ [1].

\section{MATHEMATICAL MODELLING OF A SATELLITE}

The energy transfer in the vacuum of space can be represented by the energy equation, which is a second-order partial differential equation as follows [11]:

$$
-\nabla \cdot q_{C}^{\prime \prime}-\nabla \cdot q_{R}^{\prime \prime}+q^{\prime \prime \prime}=\rho C_{p} \frac{\partial T}{\partial t}
$$

The first term on the left-hand side of the equation, $-\nabla \cdot q_{C}^{\prime \prime}$ , is the rate of energy addition per unit volume due to heat conduction. Conduction occurs from one surface to another, such as from the surface of an electronics box to the structure of the satellite. The second term, $-\nabla \cdot q_{R}^{\prime \prime}$, is the rate of energy addition due to unit volume radiative heat transfer. Finally, $q^{\prime \prime \prime}$ is the source term per unit volume, and consists of external heat flux and internal heat dissipations. In addition, $\mathrm{Cp}$ is the specific heat value, $\rho$ is the density, $\mathrm{T}$ is the temperature, and $t$ is the time. Heat transfer occurs only via radiation and conduction, due to the vacuum conditions. The actual model of the satellite contains a discrete radiative connection between them. Each discrete element in the satellite is represented by a control volume with regard to the heat flux. The discretisation of the real satellite model includes both conduction and radiation links. Each component first needs to be appropriately discretised, and heat transfer mechanisms can then be applied in a discrete way, as shown in Equations (2) and (3).

For conduction,

$$
\dot{Q}_{i \rightarrow j}=\frac{k_{i j} A_{i j}\left(T_{\dot{Y}}-T_{j}\right)}{L_{i j}}
$$

where $A_{i j}$ is the area, $k_{i j}$ is the thermal conductivity between the ith and jth components, and $L_{i j}$ is the effective distance between these components.For radiation,

$$
\dot{Q}_{i \rightarrow \text { space }}=\varepsilon . \sigma . A_{i j} \cdot \boldsymbol{F}_{i j} \cdot\left(T_{i}^{4}-T_{\text {space }}{ }^{4}\right)
$$

$F_{i j}$, the view factor between two surfaces, is commonly computed using a Monte Carlo ray-tracing method.

Thermal control of the satellite is related to the balance between energy received and emitted from the satellite. This energy balance can be written as in Equation (4):

$$
\begin{aligned}
& \dot{Q}_{\text {in }}=\dot{Q}_{\text {out }} \\
& \dot{Q}_{S}+\dot{Q}_{E, I R}+\dot{Q}_{A}+\dot{Q}_{\text {dissipated }}-\dot{Q}_{\text {radiated }}=0
\end{aligned}
$$

Based on its optical properties, such as emissivity and absorptivity, the satellite cools via radiation into deep space $\left(\dot{Q}_{\text {radiated }}\right)$.

The heat power absorbed by the satellite is determined by Equation (6):

$$
\dot{Q}_{S}=\alpha^{s} \quad A^{s} F q_{\text {solar }}
$$

and the nominal albedo value is calculated using Equation (7).

$$
\dot{Q}_{A}=\alpha^{s} A^{s} F q_{\text {solar }}
$$

The IR power of the Earth is calculated using the following 
expression:

$$
\dot{Q}_{E, I R}=\sigma T_{E}^{4} \quad \mathrm{~F} A^{s} \varepsilon_{I R}
$$

where $q_{\text {solar }}$ is the solar flux (in $\mathrm{W} / \mathrm{m}^{2}$ ), $A^{S}$ is the area of the surface $\left(\right.$ in $\left.\mathrm{m}^{2}\right), \alpha^{s}$ is the absorbtivity of the surface of the satellite, $\varepsilon_{I R}$ is the surface emissivity, and $a$ is the albedo coefficient, which depends on the inclination with respect to the summer and winter solstices. The Stefan-Boltzmann constant $\sigma$ is $5.67 \times 10^{-8} \mathrm{~W} / \mathrm{m}^{2} \mathrm{~K}^{4}$.

$$
\begin{aligned}
& C_{i} \cdot \frac{d T i}{d T}=\sigma \sum G R_{i j}\left(T_{j}^{4}-T_{i}^{4}\right)+\sum G L_{i j}\left(T_{j}-T_{i}+\right. \\
& \dot{Q}_{S}+\dot{Q}_{A}+\dot{Q}_{E, I R}+\dot{Q}_{\text {dissipated }}
\end{aligned}
$$

In the above equation, the term on the left-hand side represents the thermal capacitance of the element, where $C_{i}$ is the heat capacity, $T_{i}$ is the temperature of node $i$, and $t$ is the time. The first term on the right-hand side is the net radiation emitted, $G R_{i j}$ represents the radiation links, the second term is the internal conduction, $G L_{i j}$ represents the conduction links, $\dot{Q}_{S}, \dot{Q}_{A}, \dot{Q}_{E, I R}$ are the external loads, and the last term $\dot{Q}_{\text {dissipated }}$ is the internal heat dissipation from the electronic equipment. The total heat transfer from the satellite can be written in discrete form as follows:

$$
[\mathrm{M}] \frac{d T}{d t}=[\mathrm{R}] \vec{T}^{4}+[\mathrm{K}] \vec{T}+\dot{\vec{Q}}_{\text {ext }}
$$

where $[\mathrm{M}]$ is the diagonal mass matrix, $[\mathrm{K}]$ is the conductivity matrix, $[\mathrm{R}]$ is the radiation matrix and $\dot{\vec{Q}}_{\text {ext }}$ represents the external heating terms.

Figure 2 shows the important processes that are radiation links between two nodes and radiation links to the space node [12].

\section{THERMAL DESIGN PROCESS}

In this study, the satellite was modelled as consisting of two deployable solar panels; 22 pieces of electronic equipment comprising 18 boxes, three closed discs and one cylinder; one representative payload (camera); one separating ring; and two antennas, as shown in Figure 3.The size and material of the satellite used in our model and the locations of the equipment are as follows. The main body of the satellite is rectangular, and is made up of four aluminum honeycomb panels and two square panels. The dimensions of the main body and the two square panels are $1.0 \times 1.4 \times 0.001 \mathrm{~m}$, and $1.0 \times 1.0 \times 0.001 \mathrm{~m}$, respectively. The size of the deployable solar panels is $1.0 \times 1.2 \times 0.001 \mathrm{~m}$. While electronic equipment inside the satellite is mounted on the inner side of the main body $(+\mathrm{X})$ and $(-\mathrm{X})$ panels, and the main body $(+\mathrm{Y})$ and $(-\mathrm{Y})$ panels, some electronic equipment such as magnetometers and sun sensors are mounted on the $(-Z)$ panel outside the satellite. The antennas are also placed on the $(+Z)$ panel outside the satellite, and are represented by cones. Electronic equipment inside the satellite is symbolised by a rectangular prism, except for the reaction wheels and torque rod, which are represented by a closed disc and a cylinder,

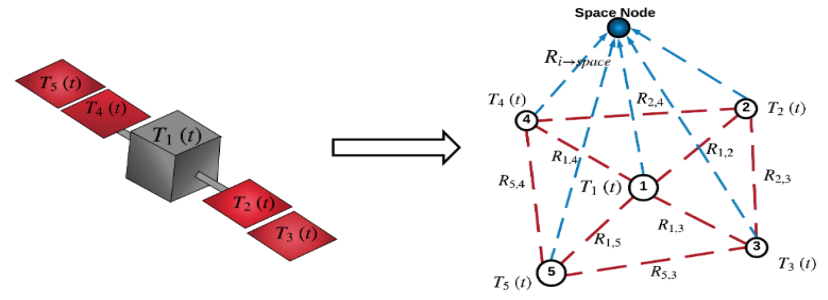

Figure 2. Schematic of the radiative network of a model satellite.

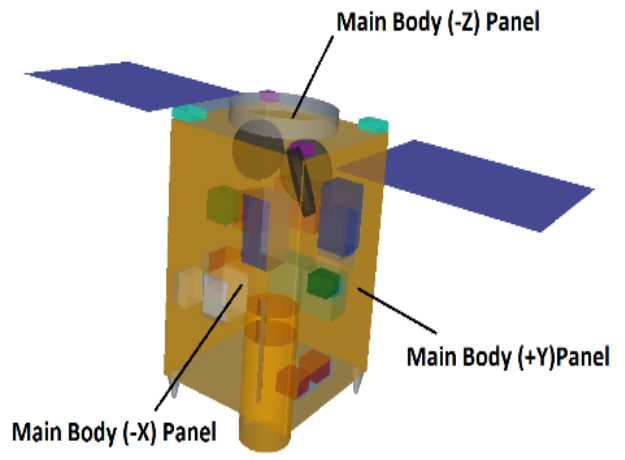

a)

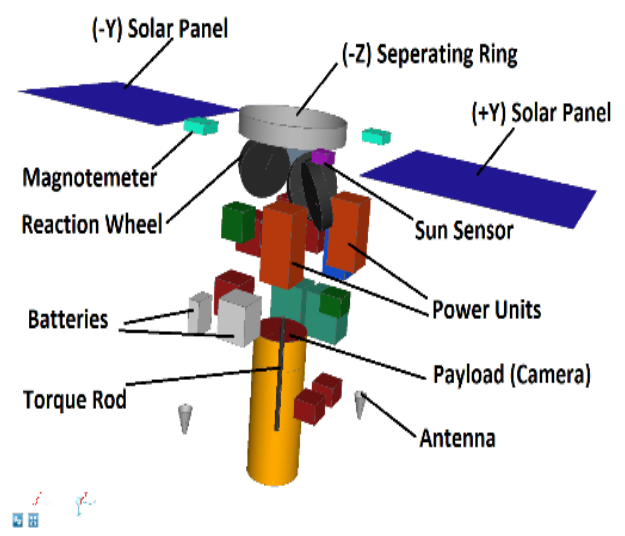

b)

Figure 3. (a) The main body of the satellite with respect to the coordinate system; (b) locations of the electronics components of the satellite.

respectively. The payload is located on the inner $(+\mathrm{Z})$ panel and is also represented by a cylinder, with dimensions of $0.30 \times 0.50 \mathrm{~m}$ (diameter and height, respectively). The main body of the satellite is considered to be made of $\mathrm{Al} 6061$, with thermal conductivity $167 \mathrm{~W} / \mathrm{mK}$ and thickness 0.001 $\mathrm{m}$. Each of the items of electronic equipment is represented as a $1 \times 1$ thermal node, and the payload is also represented by a single node, while the inner and outer side panels of the satellite are modelled as $15 \times 15$ and $25 \times 25$ respectively. The total number of mesh points used for thermal modeling was 3430, excluding space nodes. Heat resulting from the thermal and electrical processes of the electronic equipment disperse to the equipment around and medium. The heat dissipation and the numbers of nodes used to model the components of the satellite are shown in Table 1.The main body of the satellite is coated with MLI and radiators. MLI is used to prevent the overheating of equipment and the transfer of generated heat into space during the mission. Second surface mirrors (SSMs) operate as radiators whenever high solar emittance and low solar absorptance are needed in the system [13]. Thermal interface fillers are also added between 


\begin{tabular}{|c|c|c|c|c|c|c|c|}
\hline Components Name & $\begin{array}{l}\text { Node Number } \\
\text { Ranges }\end{array}$ & $\begin{array}{l}\text { Heat } \\
{[W]}\end{array}$ & $\begin{array}{c}\text { Mass } \\
{[\mathrm{kg}]}\end{array}$ & Components Name & $\begin{array}{l}\text { Node Number } \\
\text { Ranges }\end{array}$ & $\begin{array}{l}\text { Heat } \\
{[W]}\end{array}$ & $\begin{array}{c}\text { Mass } \\
{[\mathrm{kg}]}\end{array}$ \\
\hline$(+X)$ inner side & $10000-10125$ & 0 & 5 & $(-Y)$ outer side & $45000-45625$ & 0 & 5 \\
\hline$(+X)$ outer side & $15000-15625$ & 0 & 5 & Battery -2 & 410 & 10 & 4 \\
\hline Payload Electronic Box & 100 & 30 & 12.5 & Antenna Electronic Unit & 420 & 25 & 6.4 \\
\hline $\mathrm{X}$ band Communication Unit & 110 & 20 & 8 & Reaction Wheel Electronic Unit & 430 & 25 & 7 \\
\hline$S$ band Communication Unit & 120 & 20 & 8 & (-Z) Space Panel & 5000 & 0 & 3 \\
\hline Solar Panel Electronic-1 & 130 & 10 & 3.70 & Seperating Rings & 500 & 0 & 10 \\
\hline$(-X)$ inner side & $20000-20125$ & 0 & 5 & Reaction Wheel-1 & 510 & 20 & 11.35 \\
\hline$(-X)$ outer side & $25000-25625$ & 0 & 5 & Reaction Wheel-2 & 520 & 20 & 11.35 \\
\hline Power Unit-1 & 200 & 30 & 15 & Reaction Wheel-3 & 530 & 20 & 11.35 \\
\hline Battery-1 & 210 & 10 & 4 & Magnotemeter-1 & 540 & 5 & 2.5 \\
\hline Torque Rod & 220 & 4 & 2.5 & Magnotemeter-2 & 550 & 5 & 2.5 \\
\hline Altitude Cont.-1 & 230 & 4 & 3.5 & Sun Sensor-1 & 560 & 3 & 3 \\
\hline$(+Y)$ inner side & 30000-30125 & 0 & 5 & Sun Sensor-2 & 570 & 3 & 3 \\
\hline$(+Y)$ outer side & $35000-35625$ & 0 & 5 & $(+Z)$ Earth Panel & 6000 & 0 & 10 \\
\hline Power Unit-2 & 300 & 30 & 15 & Antenna-1 & 600 & 2 & 2 \\
\hline Data reservor-1 & 320 & 15 & 3.8 & Antenna-2 & 610 & 2 & 2 \\
\hline Data reservor-2 & 330 & 15 & 3.8 & Payload & 6100 & 0 & 10 \\
\hline Altitude Cont.-2 & 340 & 15 & 3.2 & Solar Panel-1 & 7000 & 0 & 10 \\
\hline$(-Y)$ inner side & $40000-40125$ & 0 & 5 & Solar Panel-2 & 8000 & 0 & 10 \\
\hline
\end{tabular}

the panels and the electronic equipment to enhance thermal conductance and prevent overheating of the equipment. The dry contact value is assumed to be $300 \mathrm{~W} / \mathrm{m}^{2} \mathrm{~K}$ between equipment and panels without using thermal interface material with high conductance values such as RTV $[1,14]$. All of the electronic equipment is coated with black paint to provide a homogeneous temperature distribution inside the satellite. However, some equipment outside the satellite is coated with first surface mirrors (FSMs), which have a low emittance and absorptance, to prevent heat loss from components such as sun sensors. The thermo-optical properties of the thermal control materials used in the satellite model are shown in Table 2 [1].

Table 2. The radiative properties of thermal control materials

\begin{tabular}{|c|c|c|c|c|}
\hline \multirow[t]{2}{*}{ Thermal Control Materials } & \multicolumn{2}{|c|}{$\begin{array}{l}\text { Absorptivity } \\
(\alpha)\end{array}$} & \multicolumn{2}{|c|}{$\begin{array}{l}\text { Emissivity } \\
(\varepsilon)\end{array}$} \\
\hline & $\mathrm{BOL}$ & EOL & $\mathrm{BOL}$ & EOL \\
\hline SSM & 0.14 & 0.24 & 0.85 & 0.85 \\
\hline FSM & 0.02 & 0.24 & 0.14 & 0.14 \\
\hline Black Paint & 0.85 & 0.85 & 0.85 & 0.85 \\
\hline Solar Panels Cell Front Side & 0.92 & 0.92 & 0.899 & 0.899 \\
\hline Solar Panels Back Side & 0.01 & 0.01 & 0.99 & 0.99 \\
\hline Payload & 0.50 & 0.50 & 0.50 & 0.50 \\
\hline MLI (Outer material is Kapton) & \multicolumn{2}{|c|}{0.49} & 0.71 & $\varepsilon^{*}: 0.02$ \\
\hline
\end{tabular}

BOL: Beginning of life of the satellite; EOL: End of life of the satellite; $\varepsilon^{*}$ : Effective emissivity of MLL.

Thermal control surfaces such as SSMs or FSMs can be affected by contamination, atomic oxygen, or strong vacuums. As a result of this situation, the absorbtivity value is increased at the end of life, whereas the emissivity is slightly affected or not affected at all [14]. In addition, active thermal control equipment such as heaters and thermistors are used in overcooling of the components. The heater power and duty cycle are determined by conducting thermal analyses. A schematic of the thermal control systems, both passive and active, is shown in Figure 4.

The temperature distributions of the electronic equipment in the satellite need to be maintained within specific ranges of operating and non-operating temperatures throughout the mission, to avoid thermal fatigue, overcooling or overheating.

The temperature requirements for each subsystem are shown in Table 3.

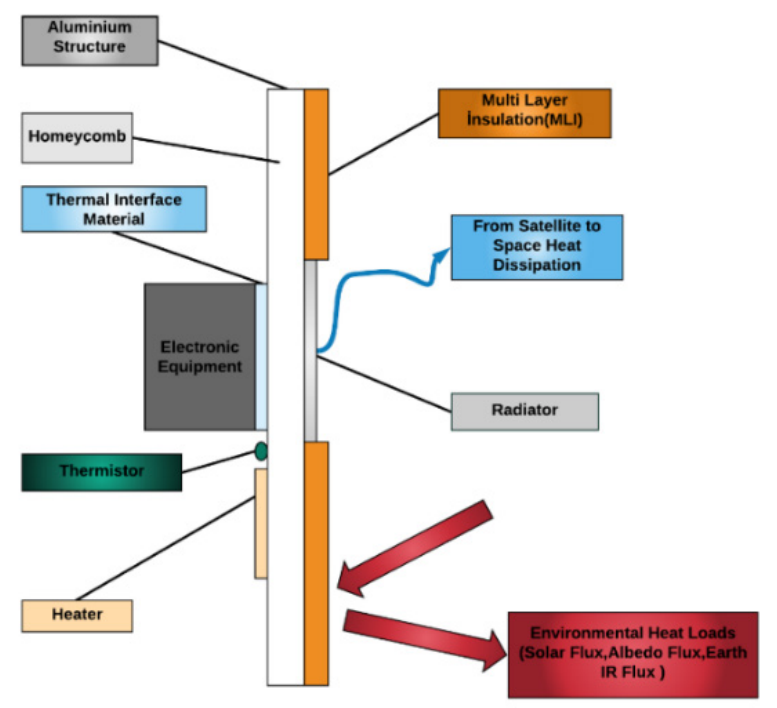

Figure 4. Schematic of the thermal control system of a satellite.

The satellite has a sun-synchronous orbit around the earth at around $840 \mathrm{~km}$. The parameters defining the orbit of the satellite are shown in Table 4. An important point in the design of the satellite is that the $(+\mathrm{Z})$ earth panel always looks towards the earth, which is known as nadir pointing, and the velocity vector is the $(+\mathrm{Y})$ panel. The position of the satellite at any time is shown in Figure 5. 
Table 3. Operating and non-operating temperatures for equipment.

\begin{tabular}{|c|c|c|}
\hline $\begin{array}{c}\text { Components } \\
\text { Batteries }\end{array}$ & $\begin{array}{c}\text { Operating } \\
\text { Temp. Range } \\
{\left[{ }^{\circ} \mathrm{C}\right]}\end{array}$ & $\begin{array}{c}\text { Non-Operating Temp. } \\
\text { Range } \\
{[0,+30]}\end{array}$ \\
\hline Power Units & {$[-20,+50]$} & {$[0,+30]$} \\
\hline Payload & {$[+10,+30]$} & {$[-30,+60]$} \\
\hline Solar Panels & {$[-100,+100]$} & {$[-100,+100]$} \\
\hline Antennas & {$[-80,+100]$} & {$[-80,+100]$} \\
\hline Magnotemeter & {$[-20,+50]$} & {$[-20,+50]$} \\
\hline Sun Sensor & {$[-20,+50]$} & {$[-20,+50]$} \\
\hline Other Electronic Equipments & {$[-20,+50]$} & {$[-20,+50]$} \\
\hline & & \\
\hline
\end{tabular}

Figure 5. The position of the satellite model at any time in the mission orbit.

Table 4. Orbital parameters for the satellite.

\begin{tabular}{|c|c|}
\hline Type of Orbit & Sun-Synchronous \\
\hline Local-Solar Time & $22: 30: 00$ \\
\hline Altitude & $840 \mathrm{~km}$ \\
\hline Anomaly & $0^{\circ}$ \\
\hline Revolution & $8 \mathrm{rev}$ \\
\hline Launch Year & 2022 \\
\hline
\end{tabular}

\section{THERMAL ANALYSIS}

A thermal analysis is used to evaluate and control the temperature distributions of the equipment while it is in orbit. The locations of electronic components need to be set in certain operating temperatures during its mission life. There are two scenarios that affect the design of a satellite thermal control system. The first is the hot case, in which the highest possible external heat flux is falling on the satellite. The objectives in this case are to calculate the required area for the radiators and to determine the most suitable locations for the radiators on the satellite. The other scenario is the cold case, in which the lowest possible external heat flux is falling on the satellite. The motivation in this case is to determine the power requirements for the heaters and thermistors. The main parameters for each scenario are listed in Table 5 $[14,15]$.

\begin{tabular}{|c|c|c|}
\hline \multicolumn{3}{|c|}{ Table 5. Parameters for the hot and cold cases. } \\
\hline Parameters & Hot Case & Cold Case \\
\hline Solar Flux & $1417 \mathrm{~W} / \mathrm{m}^{2}$ & $1326 \mathrm{~W} / \mathrm{m}^{2}\left(0 \mathrm{~W} / \mathrm{m}^{2}\right.$ for eclipse $)$ \\
\hline Albedo Factor(a) & 0.35 & 0.20 \\
\hline Earth IR & $258 \mathrm{~W} / \mathrm{m}^{2}$ & $216 \mathrm{~W} / \mathrm{m}^{2}$ \\
\hline Beta Angle $(\beta)$ & 23.59 & 17.02 \\
\hline Earth Temp. & $252.4 \mathrm{~K}$ & $248 \mathrm{~K}$ \\
\hline Absorbtivity of Radiator $(\alpha)$ & 0.24 & 0.14 \\
\hline Space Temp. & \multicolumn{2}{|c}{} \\
\hline
\end{tabular}

\subsection{Parameters of the Numerical Simulation}

Thermal analyses and simulations of the satellite model were carried out using Systema Thermica V.4.8.P1 software, developed by Airbus Defense SAS. The code calculates the thermal radiation between the nodes and the environment. The Monte-Carlo ray-tracing method is used to solve the radiative transfer equation with a high level of accuracy [16]. The external orbital radiative heat fluxes during the mission and the radiative transfer interactions between the components were calculated dynamically using Thermica. The radiation falling on and scattered from the outer surfaces was assumed to be diffuse. In the simulations, the space temperature was taken as $4 \mathrm{~K}$ [17], and the complete system was assumed to be at $273 \mathrm{~K}$ initially, in order to ensure that the system converged equally to the coldest and hottest conditions. Thermica was applied for a computational time of 47,232 s, almost equal to eight orbital periods (where one orbital simulation took 5,904 s) under the operating conditions defined in Table 4. In the simulation, the number of random rays falling onto the satellite was 876,743 , and a total of 10,000 rays were emitted from each of the representative items of equipment, the main body and the solar panels.

\section{RESULTS}

\subsection{Hot Case}

Several analyses of the hot case were carried out in order to optimise the area and locations of the radiators on the panels. In the first analysis (Case 1), the model was run without radiators on the panels and with only the use of MLI. In this case, the temperature limits for many of the electronic components were exceeded, including the payload. When radiators were added to the $(+\mathrm{X})$ panel, the temperatures dropped quickly. When three radiators were added, each with an area of $0.0625 \mathrm{~m}^{2}$, the temperature of the equipment located on the $(+\mathrm{X})$ panel decreased dramatically. For instance, the temperatures of nodes 100 and 110 dropped from $85.8^{\circ} \mathrm{C}$ to $53.82^{\circ} \mathrm{C}$ and from $84^{\circ} \mathrm{C}$ to $51.86^{\circ} \mathrm{C}$, respectively. The temperatures of nodes 120 and 130 followed a similar trend, dropping from $83.6^{\circ} \mathrm{C}$ to $50.9^{\circ} \mathrm{C}$ and from $82.34^{\circ} \mathrm{C}$ to $51.52^{\circ} \mathrm{C}$, respectively. In some areas, interface materials were used on the panels, such as RTV and CV, with thermal conductance values of $1000 \mathrm{~W} / \mathrm{m}^{2} \mathrm{~K}$ and $1750 \mathrm{~W} / \mathrm{m}^{2} \mathrm{~K}$, respectively. With the use of these materials, the thermal conductivity between the equipment and panels was enhanced, and the temperature of the equipment decreased by $2-3^{\circ} \mathrm{C}$. Finally, a radiator with an area of $0.062 \mathrm{~m}^{2}$ was added, giving a total radiator area of $0.249 \mathrm{~m}^{2}$. Similar radiators were placed on the other panels, i.e. $(-\mathrm{Y}),(-\mathrm{X})$ and $(+\mathrm{Y})$, thus completing the panel, and the total radiator areas were $0.1885 \mathrm{~m}^{2}$, $0.135 \mathrm{~m}^{2}$ and $0.1247 \mathrm{~m}^{2}$, respectively. The final locations of the radiators on the $(+\mathrm{X}),(-\mathrm{Y})$ panels and the $(-\mathrm{X}),(+\mathrm{Y})$ panels are shown in Figures 6 and 7, respectively.As a result, all of the components on the panels of the satellite remained within the allowable ranges of operating temperature for the hot case. 


\begin{tabular}{|c|c|c|c|c|c|c|c|c|c|c|c|}
\hline Cases & \multirow{2}{*}{\multicolumn{2}{|c|}{$\begin{array}{c}\text { Case-1 } \\
\text { Non-Radiators }\end{array}$}} & \multirow{2}{*}{\multicolumn{2}{|c|}{$\begin{array}{c}\text { Case-2 } \\
(+\mathrm{X}) \text { panel }\end{array}$}} & \multirow{2}{*}{\multicolumn{2}{|c|}{$\begin{array}{l}\text { Case-3 } \\
(-Y) \text { panel }\end{array}$}} & \multirow{2}{*}{\multicolumn{2}{|c|}{$\begin{array}{c}\text { Case-4 } \\
(-X) \text { panel }\end{array}$}} & \multirow{2}{*}{\multicolumn{2}{|c|}{$\begin{array}{c}\text { Case-5 } \\
(+\mathrm{Y}) \text { panel }\end{array}$}} & \multirow[t]{2}{*}{$\nabla$ Area $\left(\mathrm{m}^{2}\right.$} \\
\hline Descriptions & & & & & & & & & & & \\
\hline Radiators Area $\left(\mathrm{m}^{2}\right)$ & \multicolumn{2}{|c|}{-......... } & \multicolumn{2}{|c|}{0.249} & \multicolumn{2}{|c|}{0.1885} & \multicolumn{2}{|c|}{0.135} & \multicolumn{2}{|c|}{0.1247} & 0.6972 \\
\hline Node Number & $\mathrm{T}_{\min }$ & $\mathrm{T}_{\max }$ & $\mathrm{T}_{\min }$ & $\mathrm{T}_{\max }$ & $\mathrm{T}_{\min }$ & $\mathrm{T}_{\max }$ & $\mathrm{T}_{\min }$ & $\mathrm{T}_{\max }$ & $\mathrm{T}_{\min }$ & $\mathrm{T}_{\max }$ & $\begin{array}{l}\text { Max. } \\
\text { Temp. }\end{array}$ \\
\hline 100 & 83.76 & 85.81 & 50.37 & 51.83 & 44.53 & 47.93 & 38.76 & 42.65 & 34.07 & 38.03 & +50 \\
\hline 110 & 82.53 & 84.01 & 48.86 & 49.87 & 42.48 & 45.86 & 36.38 & 39.77 & 31.60 & 34.89 & +50 \\
\hline 120 & 82.19 & 83.68 & 47.82 & 48.91 & 42.43 & 45.77 & 36.31 & 39.66 & 31.12 & 34.39 & +50 \\
\hline 130 & 78.47 & 82.35 & 46.28 & 49.53 & 40.88 & 46.51 & 34.72 & 40.39 & 28.44 & 34.21 & +50 \\
\hline 200 & 80.60 & 82.79 & 66.15 & 68.31 & 60.52 & 63.01 & 39.76 & 42.36 & 34.67 & 37.42 & +50 \\
\hline 210 & 75.59 & 79.23 & 58.60 & 62.28 & 46.80 & 50.96 & 26.78 & 31.15 & 22.15 & 26.51 & +30 \\
\hline 220 & 74.17 & 77.03 & 57.02 & 59.68 & 50.12 & 53.18 & 34.20 & 37.41 & 28.02 & 31.54 & +50 \\
\hline 230 & 71.71 & 76.16 & 55.27 & 59.79 & 48.64 & 53.75 & 39.86 & 45.01 & 33.73 & 39.35 & +50 \\
\hline 300 & 79.87 & 82.49 & 63.81 & 66.41 & 58.64 & 61.63 & 52.10 & 55.08 & 36.62 & 39.92 & +50 \\
\hline 320 & 83.72 & 85.62 & 70.40 & 72.12 & 64.81 & 66.86 & 58.47 & 60.53 & 41.51 & 44.26 & +50 \\
\hline 330 & 84.20 & 85.98 & 71.69 & 73.37 & 66.10 & 68.03 & 59.24 & 61.17 & 41.88 & 44.40 & +50 \\
\hline 340 & 88.28 & 90.34 & 72.33 & 74.51 & 66.82 & 69.33 & 59.88 & 62.39 & 44.86 & 47.69 & +50 \\
\hline 410 & 82.87 & 84.50 & 69.12 & 70.66 & 33.60 & 36.99 & 26.61 & 30.89 & 22.85 & 27.40 & +30 \\
\hline 420 & 84.53 & 87.56 & 67.97 & 70.85 & 49.12 & 54.87 & 43.38 & 49.17 & 38.22 & 44.20 & +50 \\
\hline 430 & 84.80 & 86.84 & 68.47 & 70.84 & 50.30 & 54.62 & 44.07 & 48.41 & 38.24 & 42.74 & +50 \\
\hline 510 & 72.49 & 76.65 & 4.84 & 22.33 & 52.01 & 57.13 & 45.52 & 50.66 & 41.23 & 46.20 & +50 \\
\hline 520 & 74.00 & 77.96 & 57.27 & 62.29 & 55.29 & 59.87 & 47.32 & 51.92 & 42.32 & 46.79 & +50 \\
\hline 530 & 75.48 & 78.99 & 60.02 & 64.51 & 53.95 & 58.28 & 47.66 & 52.00 & 42.57 & 46.76 & +50 \\
\hline 540 & 31.06 & 51.10 & 59.01 & 63.25 & 25.90 & 47.86 & 24.39 & 46.38 & 23.43 & 45.35 & +50 \\
\hline 550 & 24.50 & 45.99 & 25.63 & 45.89 & 19.18 & 43.65 & 17.60 & 42.10 & 16.57 & 41.03 & +50 \\
\hline 560 & 30.27 & 39.24 & 19.13 & 40.76 & 25.38 & 34.99 & 23.93 & 33.55 & 22.98 & 32.56 & +50 \\
\hline 570 & 37.74 & 46.57 & 25.05 & 34.14 & 33.24 & 43.11 & 31.92 & 41.78 & 31.04 & 40.87 & +50 \\
\hline 600 & 27.40 & 33.80 & 22.80 & 28.62 & 23.94 & 30.12 & 23.49 & 29.67 & 23.20 & 29.36 & +50 \\
\hline 610 & 16.08 & 21.70 & 7.49 & 12.49 & 8.39 & 14.71 & 7.82 & 14.13 & 7.42 & 13.72 & +50 \\
\hline 6100 & 32.89 & 62.60 & 11.45 & 43.75 & 6.88 & 41.44 & 3.12 & 38.04 & -1.73 & 24.2 & +30 \\
\hline 7000 & -58.6 & 52.91 & -60.5 & 50.92 & -58.9 & 52.93 & -58.9 & 52.93 & -58.1 & 52.97 & +100 \\
\hline 8000 & -58.7 & 52.84 & -60.7 & 50.86 & -58.1 & 52.94 & -58.2 & 52.91 & -58.2 & 52.87 & +100 \\
\hline
\end{tabular}

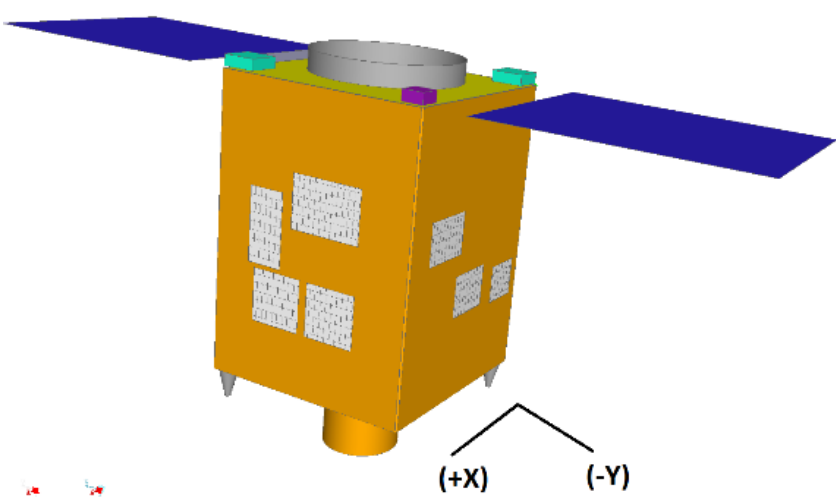

Figure 6. Radiator locations on the $(+X)$ and $(-Y)$ panels.

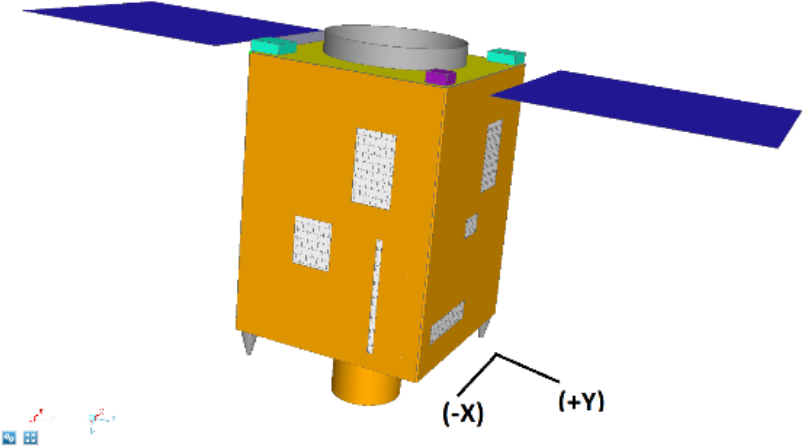

Figure 7. Radiator locations on the $(-X)$ and $(+Y)$ panels.

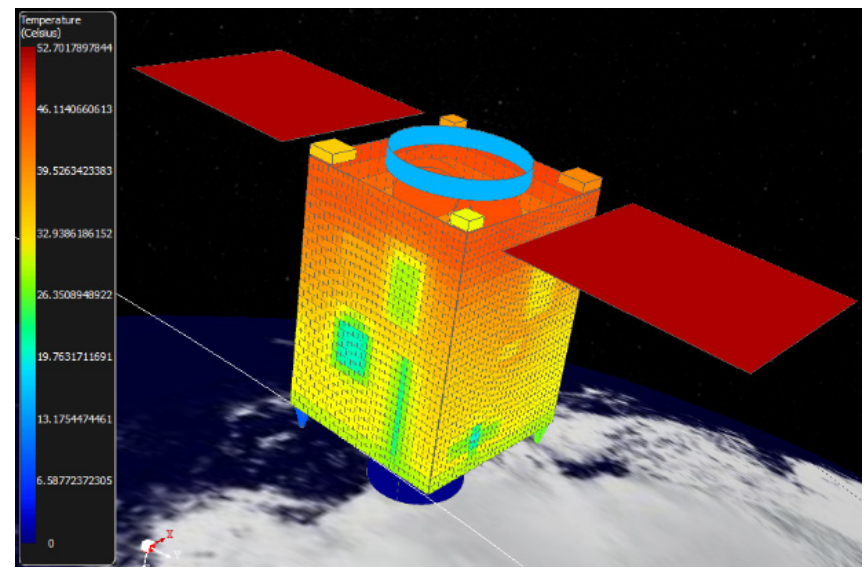

Figure 8. Instantaneous temperature of the satellite at the winter solstice (hot case) and the effects of the radiators.

\subsection{Cold Case}

The addition of radiators to the panels to handle the hot case may result in the overcooling of some critical electronic equipment such as batteries. In the first analysis, the panel of the satellite was studied with no heaters or thermistors. At the end of this analysis, the batteries were too cold: the temperature of Battery 1, represented by node 210 , was $-14.6^{\circ} \mathrm{C}$ , while the temperature of Battery 2 (node 410 ) was $-5.7^{\circ} \mathrm{C}$. It was therefore necessary to add a suitable number of heaters 
Table 7. The use of heaters for Battery 1:Three cases

\begin{tabular}{|c|c|c|c|c|c|c|c|c|c|}
\hline Cases & $\begin{array}{c}\text { Heater1 } \\
\text { Power } \\
(\mathrm{W})\end{array}$ & $\begin{array}{c}\text { Heater1 } \\
\text { Duty Cycle } \\
(\%)\end{array}$ & $\begin{array}{c}\Sigma \\
\text { Heater1 } \\
\text { Power } \\
(\mathrm{W})\end{array}$ & $\begin{array}{c}\text { Heater2 } \\
\text { Power } \\
(\mathrm{W})\end{array}$ & $\begin{array}{c}\text { Heater1 } \\
\text { Duty } \\
\text { Cycle } \\
(\%)\end{array}$ & $\begin{array}{c}\text { Q Heater2 } \\
\text { Power } \\
(\mathrm{W})\end{array}$ & $\begin{array}{c}\text { Total } \\
\text { Heaters } \\
(\mathrm{W})\end{array}$ & $\begin{array}{c}\text { Battery-1 } \\
\text { Temp. }\left({ }^{\circ} \mathrm{C}\right)\end{array}$ \\
\hline Case-1 & 9 & $100 \%$ & 9 & 18 & $100 \%$ & 18 & 27 & $(+2.43,+5.15)$ \\
\hline Case-2 & 21 & $63.20 \%$ & 13.272 & 18 & $100 \%$ & 18 & 31.272 & $(+6.31,+11.38)$ \\
\hline $\begin{array}{c}\text { Case-3 } \\
\text { (Ideal) }\end{array}$ & 21 & $84.22 \%$ & 17.86 & 9 & $80 \%$ & 7.2 & 25.06 & $(+6.14,+10.91)$ \\
\hline Case-4 & 15 & $100 \%$ & 15 & 9 & $100 \%$ & 9 & 24 & $(++15)$ \\
\hline
\end{tabular}

and thermistors to the panel for the batteries. These additional heaters ensured a temperature range of between $5^{\circ} \mathrm{C}$ and $15^{\circ} \mathrm{C}$ : when the temperature of the battery was below $5^{\circ} \mathrm{C}$, the thermistor was automatically turned on, and when its temperature rose above $15^{\circ} \mathrm{C}$, it was turned off.

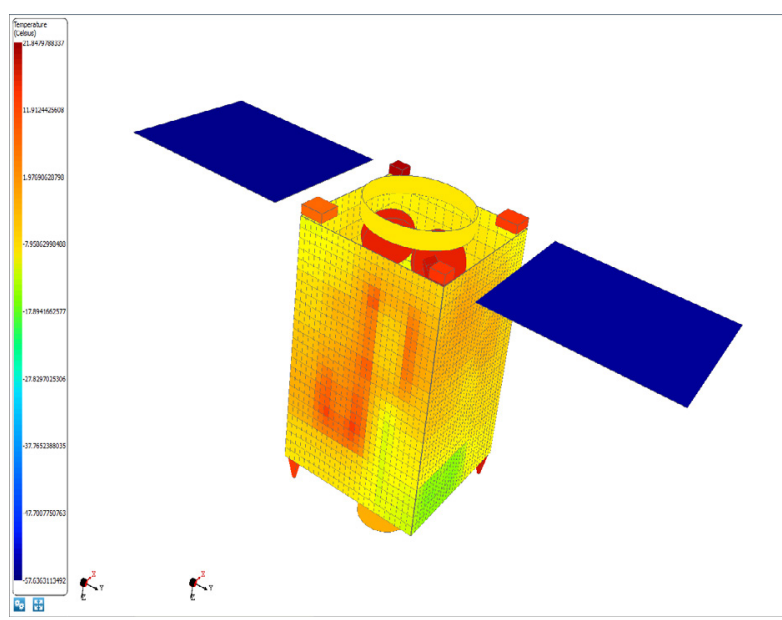

Figure 9. The effect on Battery 1 of the addition of heaters to the panels.

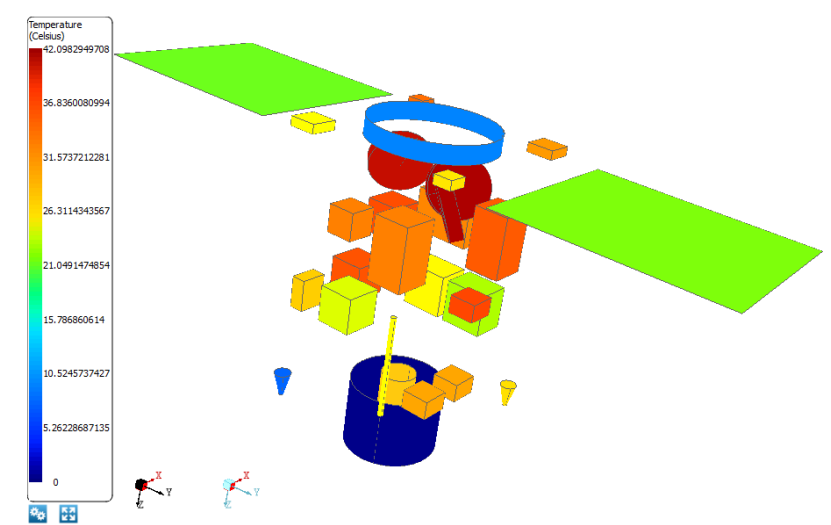

Figure 10. The temperature of the equipment located within the satellite over time.

It is also essential to consider the budget when applying heaters. For this reason, four analyses with different levels of heating power and duty cycles were carried out for Battery 1.

In case 1 , two heaters with a power of $9 \mathrm{~W}$ were used, one of which operated continuously while the other was switched on when the temperature of Battery 1 dropped below $5^{\circ} \mathrm{C}$. In case 2 , the heaters maintained the desired temperature of Battery 1, but power of the heaters was high, and one of the heaters operated continously.

The desired temperature of Battery 1 was reached by consuming the minimum power in case 3 . The cases for Battery 1 are shown in Table 7 .

\section{CONCLUSIONS}

In this study, an observation satellite in LEO was designed based on the thermal operating conditions. Various simulations were performed for two critical scenarios affecting the satellite design. The locations and areas of the radiators were optimised using thermal analyses. Due to the high emissivity of the material of the radiators, the satellite can operate in deep space, and hence the temperature of the equipment may be very low. When the total area of the radiator was $0.6972 \mathrm{~m}^{2}$, heaters needed to be used to reach the desired temperatures. The power of these heaters was calculated as 25.06 W for Battery 1.

The desired design temperature of the battery was achieved by utilising a thermistor to control the heaters automatically. The radiator area and optimisation are essential for the hot scenario. It is also necessary to consider the duty cycle of the heaters for the cold scenario. In this study, we showed how to achieve the detailed thermal design and control of a satellite that incorporated the effects of radiators and heaters.

In conclusion, this model can safely be used in the thermal design of new observation satellites when it has been validated using a thermal balance test.

\section{REFERENCES}

[1] Gilmore, D.G.( 2002). Spacecraft Thermal Control Handbook. The Aerospace Corporation, El Segundo, California.

[2] Fishwick, N.A.Smith K.A.Perez.J.A. (2015). Lessons Learned from Thermal Vacuum Testing of LISA Pathfinder over three system level Thermal Tests.International Conference on Environmental Systems. ICES 2015-246

[3] Coker, R.F. (2013). Thermal Modeling in Support of the Edison Demonstration of Smallsat Networks Project.43rd International Conference on Environmental Systems (ICES). doi:10.2514/6.2013-3368.

[4] Moffitt, B.A.,Batty,J.C. (2002). Predictive Thermal Analysis of the Combat Sentinel Satellite.16th AIAA/USU Conference on Small Satellites, Logan, Utah.

[5] Bulut, Kahriman, A, Sozbir,N. (2010). Design and Analysis for Thermal Control System of Nanosatellite.ASME 2010 International Mechanical Engineering Congress \& Exposition.

[6] Mishra, H.V. (2018). Thermal Control Subsystem for CubeSat in Low Earth Orbit.IRJET 2018 International Research Journal of Engineering and Technology, 946-949.

[7] Tsai, J.R. (2004). Overview of Satellite Thermal Analytical Model. Journal of Spacecraft and Rockets, 41(1):120-125. doi:10.2514/1.9273.

[8] Garzon, M.M. (2012). Development and Analysis of The Thermal Design For the OSIRIC-3U Cubesat, A Master Thesis in Aerospace 
Engineering,Penn State University.

[9] Hurman,J.L. (2012).Optimization of steady-state thermal design of space radiators. Journal of Spacecraft and Rockets 6:10. doi: $10.2514 / 3.29773$

[10] Aslanturk, C. (2006). Optimization of a central-heating radiator. American Institute of Aeronautics and Astronautics. 6:10 doi: $10.2514 / 3.29773$

[11] Doner, N. (2014). M1 Model for Radiative Heat Transfer in Absorbing, Emitting, and Scattering Medium, International Journal of Thermal Sciences, Volume 79,34-39.

[12] Aksu,A.Sundu.H,Mermer,E. (2019) Nonlinear system identification for the thermal management of communication satellites EUCASS2019 doi:10.13009/ EUCASS2019-910

[13] Sharma, A.K. (2013). Surface Engineering For Thermal Control of Spacecraft. Journal Surface Engineering, 21(3): 249-253. doi: $10.1179 / 174329405 \times 50118$

[14] Thermica User's Manual, Version 4.8.0.P1.

[15] Lauga, R.P. (2017). Using real Earth Albedo and Earth IR Flux for Spacecraft Thermal Analysis, 47th International Conference on Environmental Systems(ICES)-2017-142

[16] Vujičić, M. R., Lavery, N. P., \& Brown, S. G. R. (2006). Numerical sensitivity and view factor calculation using the Monte Carlo method. Proceedings of the Institution of Mechanical Engineers, Part C: Journal of Mechanical Engineering Science, 220(5), 697-702.

[17] Iucci, N., Dorman, L. I., Levitin, A. E., Belov, A. V., Eroshenko, E. A., Ptitsyna, N. G., \& Tyasto, M. I. (2006). Spacecraft operational anomalies and space weather impact hazards. Advances in Space Research, 37(1), 184-190. 